\title{
In Vitro Comparative Analysis of Antibacterial Activity of Different Fractions of Corchorus capsularis and Corchorus olitorius Leaves Extracts
}

\author{
Riad Raihan Abir ${ }^{1}$, Mafruha Marjia ${ }^{1}$, Nadira Naznin Rakhi ${ }^{1,2}$, Otun Saha ${ }^{1}$, M Anwar Hossain ${ }^{1}$ and \\ M Mizanur Rahaman ${ }^{1 *}$ \\ ${ }^{I}$ Department of Microbiology, University of Dhaka, Dhaka 1000, Bangladesh; ${ }^{2}$ Department of Biotechnology \& Genetic Engineering, Bangabandhu Sheikh \\ Mujibur Rahman Science \& Technology University, Gopalganj, Bangladesh.
}

\begin{abstract}
High prevalence of antibiotic resistance is necessitating the investigation of novel antimicrobials from natural herbs and plant. So, this present study investigated two of indigenously cultivated jute plants, Corchorus capsularis (white jute)and Corchorus olitorius (tossa jute) for their antibacterial activity. Lipophilic extracts of leaves were prepared and fractionated by column chromatography resulting in 6 fractions of the extract of $\boldsymbol{C}$. olitorius leaves (At, Bt, Ct, Dt, Et and Ft) and 11 fractions in case of white jute leaves (Aw, Bw, Cw, Dw, Ew, Fw, Gw, Hw, Iw, Jw and Kw). Each fraction of both of the leaves extracts were used to tested by agar well diffusion assay against Staphylococcus aureus and Escherichia coli along with a control organism, E. coli DH5 \pm . While the fractions of $C$. olitorius leaves showed higher antibacterial activity against $S$. aureus, fractions of the extract of $C$. capsularis leaves were more effective against $E$. coli. The At fraction of $C$. olitorius extract showed the highest inhibition zone of $19 \pm 2.80 \mathrm{~mm}$ against $S$. aureus and Dw fraction of $C$. capsularis extract had the highest inhibition zone of $15 \pm 2.3 \mathrm{~mm}$ against $E$. coli ( $p$ $<0.05$ ). The extract of $C$. olitorius leaves showed comparatively higher antibacterial effect than that of $C$. capsularis leaves. Considering the promising finding regarding the antibacterial effectiveness, these fractions of the leave extract should be analyzed further to isolate the exact bioactive component to develop the lead component of new generation antibacterial drugs.
\end{abstract}

\section{Introduction}

Antibiotic resistance is of prime public health concern worldwide and especially for countries like Bangladesh having the high prevalence of antibiotic resistance with high selective pressure leading to the development of antibiotic resistance due to misuse and/or overuse of antibiotics. The recent reports of emerging antibiotic resistance genes, especially the genes conferring the resistance to the last resort antibiotics such as carbapenems has made the scenario even worse for Bangladesh ${ }^{1-2}$. So, it is high time we should search for alternative options to the existing antibiotics. And bioactive molecules from different medicinal herbs and plants have already gained attention as an alternative regimen and already been reported to yield better results than antimicrobials from combinatorial chemistry and synthetic procedures $^{3}$. Different herbal preparations have also been being used for treatment of ailments since ancient times ${ }^{4}$.

Jute (Corchorus spp.) is a cash crop in Bangladesh being cultivated in $10 \%$ of agricultural land area ${ }^{5}$. Both Corchorus capsularis (white jute) and Corchorus olitorius (tossa jute) are being cultivated. And Corchorus capsularis (white) is valued more than Corchorus olitorius (tossa) regarding nutritive use ${ }^{6}$. Apart from nutritive values and economic importance, jute has been traditionally being used as an herbal medicine to control or prevent dysentery, worm and constipation etc. Jute leaves are rich in vitamins, carotinoids, calcium, potassium and dietary fibers and have been reported to have antitumor ${ }^{7}$ and phenolic antioxidative compounds ${ }^{8}$. Even the aqueous and methanolic extracts of C. olitoriushave antibacterial activity against Escherichia coli, Klebsiella pneumoniae, Salmonella typhiand Staphylococcus aureu ${ }^{9}$.

The isolation and characterization of bioactive compounds, especially the phenolic compounds which are rich in jute leaf extract are dependent on the extraction condition and specifically the solvent type used for the extraction ${ }^{10}$.Antioxidant properties of hydrophilic extract (water) and lipophilic extract (hexane) of C. olitoriushas already been reported ${ }^{11}$.Total phenol, total flavonoid, non-flavonoid polyphenols, and ascorbic acid mainly pertain antioxidant property of the hydrophilic extract, while the high total carotenoid content of the lipophilic extract is probably responsible for the same property ${ }^{11}$. Both ethanol and methanol are widely used as the solvents due to their qualitatively and quantitatively efficiency for phenolic compound extraction. In our study, the lipophilic solvent n-hexane was used to determine the antibacterial activity of different fractions.

While the most of the existing reports are about $\mathrm{C}$. olitorius, the other species, C. capsularis has not been extensively studied for their phytochemical properties to the best of our knowledge. On the other hand, even if the antibacterial effects of these leaf extracts have been reported, there are very few reports of systemic

*Corresponding author:

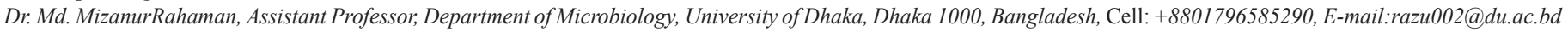


analysis of the bioactive molecule responsible for the antibacterial activity. Therefore, this study targeted to investigate both the species of Corchorus to compares their antibacterial activity against both Gram-positive and Gram-negative bacteria. Phase separation by chromatography techniques was used to imply about the bioactive molecule of these leave extracts.

\section{Materials and Methods}

Sample preparation: Leaves of both white jute and tossa jute were collected and processed in a same manner. At first the collected leaves were washed with distilled water and dried under constant heat at $30^{\circ} \mathrm{C}$ for 1 week. The shade dried leaves were powdered using a mechanical grinder and blender which converted them into powder form.

Extraction of bioactive compounds: The $70 \% \mathrm{n}$-hexane was used as the solvent for extraction of bioactive compounds. $30 \mathrm{~g}$ of each powdered samples were soaked into $150 \mathrm{~mL}$ of each of the solvents and kept at room temperature for 2 weeks. After 2 weeks the soaked samples were filtered using cotton wool filtration and Whatman Filter Paper Grade 1 filters to filtrate out the extracted samples. The filtered samples were then passed into rotary evaporator to dry out the existing solvents from the samples to isolate the extract for further experiment.

Fractionation of leaf extracts: Both thin-layer chromatography and silica gel column chromatography were applied to fractionate the leaf extracts as previously described ${ }^{12}$. In both chromatography techniques, silica gel was used as stationary phase and the mixture of chloroform and methanol was used as the mobile phase. Thin layer chromatography (TLC) of leaf extracts was firstly done to determine the total fractions from each extract. TLC plates were exposed under short and long length wavelength UV light to detect the separated components. Rf (retention factor) for each component separated by the chromatography technique was calculated by the following equation:

$\mathrm{Rf}=($ distance traveled by the compound $) /($ distance traveled by solvent front)

On the other hand, silica gel column chromatography was done using two different preparations of chloroform (C) and methanol
(M), $\mathrm{C}: \mathrm{M}=99: 1$ and $\mathrm{C}: \mathrm{M}=95: 5$ as solvents for $C$. capsularis and $\mathrm{C}: \mathrm{M}=99: 1$ for $C$. olitorius leaves extract. Column chromatography was done to collect and isolate each fraction from each of jute leaves extracts. After collecting each fraction (1-3 mL), these fractions were again subject to thin layer chromatography for confirming the separation of the components. The alike or same fractions were combined on the basis of TLC experiments ${ }^{12}$.

Antibiotic susceptibility test: Fractions separated and confirmed by chromatography techniques were evaporated by rotatory evaporator for excluding the solvent from the fractions. Later this dried preparation of both white jute leaves extract and tossa jute leaves extract were used to test for antimicrobial activity by agar well diffusion method ${ }^{13-14}$. For this test, two test isolates including a single Gram-positive isolate $S$. aureus and a single Gram-negative isolate, E. coli strain DH69 (NCBI Accession No.:MN620472) were taken from Microbial genetics and Bioinformatics Laboratory (MGBL) at University of Dhaka, Bangladesh. E. coli DH5 \pm was used as the control organism.

Statistical analyses: All the measurements were carried out in duplicate. The mean values and standard deviations were calculated and the data were expressed as mean $\pm \mathrm{SD}$. The data analysis and statistical analysis were done using SPSS software ${ }^{15}$. Differences were considered significant at the $p<0.05$ level.

\section{Results}

TLC plate visualization for estimating separate components: The n-hexane extracts of $C$. capsularsis and $C$. olitorius were subject to thin layer chromatography (TLC) for estimating the separate components of these extracts. Under short and long wavelength UV light exposure, C. capsularis showed six bands having Rf values ranged from 0.11 to 0.80 with the solvent composed of $\mathrm{C}: \mathrm{M}=99: 1$ and six bands having Rf values from 0.14 to 0.7 with the solvent (Table 1). On the other hand, C. olitorius gave five bands having $\mathrm{Rf}$ values from 0.21 to 0.79 with the solvent composed of C:M $=99: 1$ and four bands with the solvent $\mathrm{C}: \mathrm{M}=$ 95:5 having Rf values from 0.43 to 0.72 (Table 1).

Column chromatography of the extract resulted into a total of eleven fractions (Aw, Bw, Cw, De, Ew, Dw, Fw, Fw, Gw, Hw, Iw and $\mathrm{Jw}$ ) from C. capsularis, while the first five fractions

Table1. $R f$ values of different fractions obtained from the extracts of jute leaves determined by thin layer chromatography

\begin{tabular}{|c|c|c|c|c|}
\hline \multirow{2}{*}{$\begin{array}{l}\text { Extracts } \\
\text { Solvent composition }\end{array}$} & \multicolumn{2}{|c|}{ White jute leaves (C. capsularis) } & \multicolumn{2}{|c|}{ Tossa jute leaves (C. olitorius) } \\
\hline & C:M99:1 & C:M95:5 & C:M99:1 & C:M95:5 \\
\hline \multirow[t]{6}{*}{ Rf values of the fractions } & 0.11 & 0.14 & 0.21 & 0.43 \\
\hline & 0.18 & 0.28 & 0.35 & 0.48 \\
\hline & 0.3 & 0.39 & 0.42 & 0.53 \\
\hline & 0.47 & 0.54 & 0.62 & 0.72 \\
\hline & 0.74 & 0.62 & 0.79 & - \\
\hline & 0.8 & 0.71 & - & - \\
\hline
\end{tabular}


were derived with a mobile phase of $C: M=99: 1$ and the rest of the fractions were obtained with the mobile phase of $C: M=$ 95:5. On the other hand, six fractions (At, Bt, Ct, Dt, Et, Ft) from $C$. olitorius were isolated with the mobile phase of $\mathrm{C}$ : $\mathrm{M}=99: 1$.

Antimicrobial potential of the collected fractions: Agar well diffusion test of 11 fractions of $C$. capsularis collected from column chromatography showed that only 3 out of 11 fractions (Aw, Dw and Gw) had antibacterial effect against $S$. aureus, while all but only 4 fractions (Aw, Fw, Hw, Jw) produced inhibition zones in case of $E$. coli strain DH69 (Table 2). Fraction Jw lacking antibacterial activity showed no inhibition zone either against the control E. coli DH5 \pm or any of the tests. Fractions of $C$. capsularis leaves extracts were more active against Gramnegative E. coli isolates compared to Gram-positive $S$. aureus isolate.

On the other hand, fractions of $C$. olitorius (tossa jute) leaves were found more active against $S$. aureus than $E$. coli isolates (Table 3). Dt fraction of the extract showed no antibacterial activity against the tested organisms. The At fraction showed the highest zone of inhibition $(19 \pm 2.80 \mathrm{~mm})$ against $S$. aureus, while the Et fraction gave the highest inhibition zone $(15 \pm 2.58 \mathrm{~mm})$ against $E$. coli strain DH69. Ampicillin was used as the positive control for the experiment. Figure 1 shows the comparative antibacterial effects of different fractions of two of the jute spp. against test isolates.

Table 2.Mean \pm standard deviation diameter $(\mathrm{mm})$ of inhibition zones produced by the fractions of Corchorus capsularies (white jute) leaves collected from colum chromatography

Sample Organisms

\begin{tabular}{lccc}
\hline Fractions & Staphylococcus aureus & Control organismEscherichia coli DH5 \pm & Escherichia coli \\
\hline Aw & $10 \pm 0.10$ & $10 \pm 1.20$ & 0 \\
Bw & 0 & $9.5 \pm 2.1$ & $12 \pm 0.32$ \\
Cw & 0 & $12 \pm 0.90$ & $13.5 \pm 1.16$ \\
Dw & $12 \pm 1.61$ & $5.5 \pm 0.14$ & $15 \pm 2.3$ \\
Ew & 0 & $18 \pm 1.81$ & $9 \pm 0.41$ \\
Fw & 0 & $12.5 \pm 0.67$ & 0 \\
Gw & $9 \pm 0.6$ & 0 & $13.5 \pm 1.32$ \\
Hw & 0 & 0 & 0 \\
Iw & 0 & $6 \pm 0.81$ & $7 \pm 0.24$ \\
Jw & 0 & 0 & 0 \\
Kw & 0 & $8 \pm 0.73$ & $10.5 \pm 1.8$ \\
\hline
\end{tabular}

Table 3. Mean \pm standard deviation diameter of inhibition zones ( $\mathrm{mm}$ ) produced by different fractions of C. olitorius (Tossa jute) leaves obtained by column chromatography

\begin{tabular}{lccc}
\hline Sample & \multicolumn{3}{c}{ Organisms } \\
\cline { 2 - 4 } Fractions & Staphylococcus aureus & Control organism:Escherichia coli DH5 \pm & Escherichia coli \\
\hline At & $19 \pm 2.80$ & $5 \pm 0.30$ & $9.5 \pm 0.60$ \\
$\mathrm{Bt}$ & $11.5 \pm 0.34$ & $9 \pm 0.70$ & $12 \pm 1.59$ \\
$\mathrm{Ct}$ & $14 \pm 1.03$ & $7 \pm 0.3$ & $11.5 \pm 2.38$ \\
$\mathrm{Dt}$ & 0 & 0 & 0 \\
$\mathrm{Et}$ & $9 \pm 0.82$ & $13 \pm 0.96$ & $15 \pm 2.58$ \\
$\mathrm{Ft}$ & 0 & $6 \pm 0.53$ & 0 \\
\hline
\end{tabular}



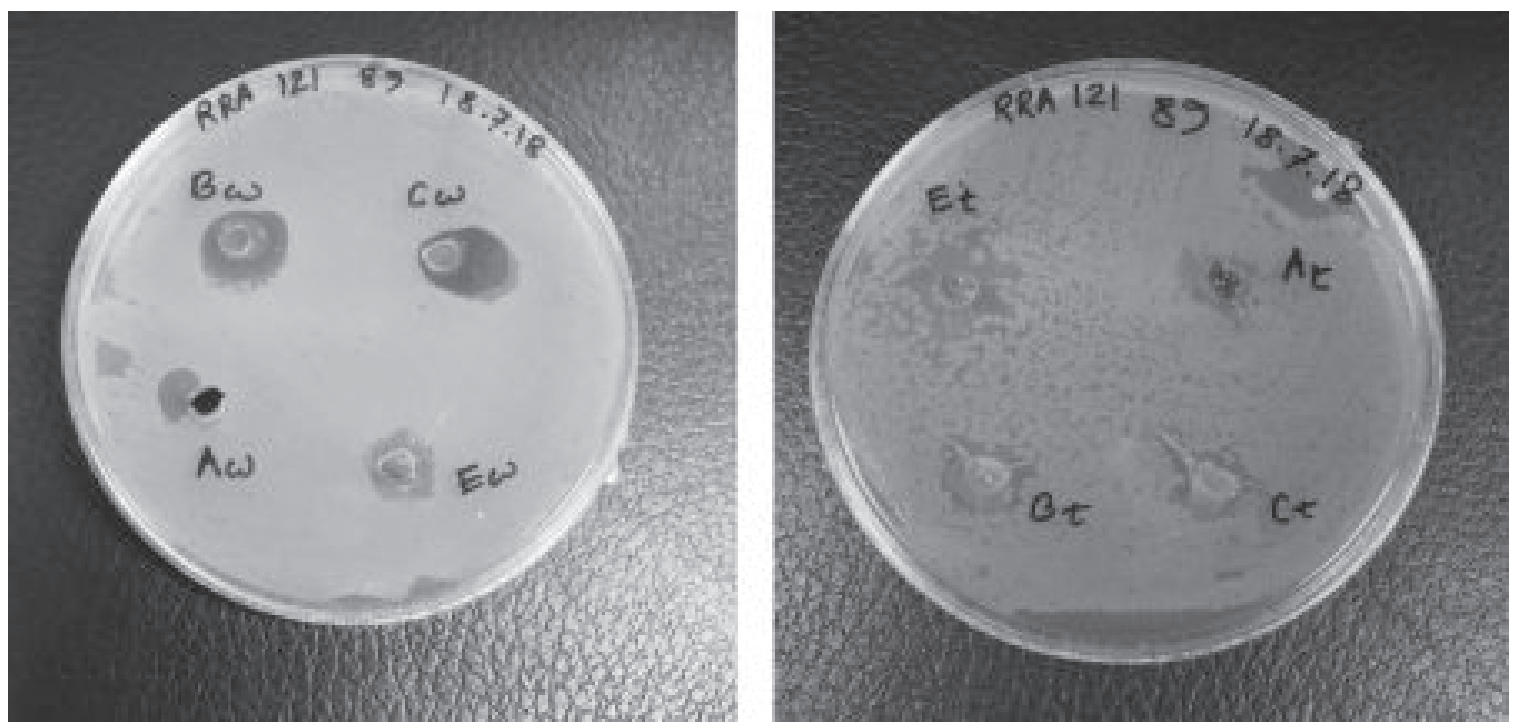

Figure 1. Representative pictures of agar well diffusion test for determining inhibition zones produced by different fractions of leaf extracts of both of the jute spp. against the test organisms. Here, a presents the inhibition zones produced by Aw, Bw, $C w$ and Ew fractions of C. capsularis (white jute) leaves extract against S. aureus, while b represents inhibition zones produced by At, Bt, Ct and Et fractions of C. olitorius (tossa jute) leaves extract against E. coli strain DH69.

\section{Discussion}

Phytochemicals are being considered as the attractive sources of natural antimicrobial compounds to combat the upcoming challenge of public health regarding antibiotic resistance. Different herbs and roots, shoots, leaves, barks of medicinal trees have been being used for medical purposes since ancient times. Jute is an indigenous plant in Bangladesh with great economical and nutritive value ${ }^{16}$. Jute leaves have been used for ascites, pain, piles, tumor, cystitis, dysuria, fever, and even in case of gonorrhea ${ }^{16}$. From the use of jute leaves for gonorrheal infection clearly implies its antimicrobial potential. The phytochemical analysis of the leaves of $C$. capsularis (white jute) showed the presence of flavonoids, saponins, tannins, steroids, triterpenes, vitamin, carotenoid, calcium, potassium and dietary fiber along with two functional compounds; phytol (3,7,11,15-tetramethyl2-hexadecen-1-ol) and monogalactosyldiacylglycerol (1,2-di-O\pm -linolenoyl-3-2 ${ }^{2}$-D-galactopyranosyl-glycerol) ${ }^{16}$. On the other hand, flavones compounds found in the $C$. olitoriushave also been reported to have the inhibitory effect on microbes by interfering with the bacterial enzymes needed for essential metabolic reactions ${ }^{8}$.

Extraction conditions and the solvent type influence the antimicrobial activity of jute leaves indicating the biochemical nature of the active compounds. Crude methanolic extract of the leaves of C. capsulais showing antifungal and antibacterial effects have inhibitory effects against both Gram-positive bacteria (Bacillus subtilis, Staphylococcus aureus, Beta hemolytic streptococcus, Bacillus cereus and Streptococcus pyrpgen), Gram-negative bacteria (Shigella boydii, Salmonella typhi E. coli, Klebsiella and Vibrio mimicus) along with yeast and fungi (Candida albicans, Saccharomyces cerevisiae and Bacillus megaterium $)^{14,17}$. But the lipophilic extract of the leaves have not yet been studied extensively. Besides, the exact composition of the active compounds has not been analyzed and reported to the best of our knowledge. That is why the present study targeted the fractionation of the leaf extract of both C. capsularis and $C$. olitorius, both of which are indigenously grown at large scale in Bangladesh. Chromatography technique with chloroformmethanol mixture was used to separate different fractions. The fractions of the leaf extract of $C$. olitorius showed better antibacterial activity against Gram-positive $S$. aureus than Gramnegative E. coli, which is consistent with a previous report ${ }^{7}$. However, all but one fraction of the extract of $C$. olitorius leaves showed the general pattern of better antibacterial activity against Gram-positive isolate compared to Gram-negative. As chloroform solubilizes nonpolar compounds and methanol solubilizes polar compounds, the polarity of themobile phase composed of chloroform-methanol mixture might have influenced the separation of the bioactive component of that specific fraction leading to this exceptional phenomenon. On the contrary, the fractions of C. capsular are found more effective against Gramnegative $E$. coli than Gram-positive $S$. aureus. Besides, the nonpolar fraction of methnolic extract of $C$. capsularis was reported to have highest antimicrobial effect with a zone of only 0.9-1.5 $\mathrm{mm}^{17}$. But in our study, the highest diameter of the zone of inhibition found was $18 \pm 1.81 \mathrm{~mm}$ against $E$. coli $\mathrm{DH} 5 \pm$, the control organism followed by $13.5 \pm 1.32 \mathrm{~mm}$ against the test isolate of E. coli. The composition of the solvent along with the purity of the component by the extraction process may be responsible for better antibacterial activity. Even though the exact biochemical nature of the bioactive compounds has not been identified in this study, the comparative analysis of antibacterial 
effects of different fraction indicates the nature of polarity of the active compounds. So, this study will help to isolate and characterize the exact component of the antibacterial potential for developing an attractive treatment alternative.

\section{Acknowledgement}

The financial assistance of the University Grants commission of Bangladesh for funding this research is acknowledged.

\section{References}

1. Rakhi NN, Alam ASMRU, Sultana M, Rahaman MM, Hossain MA. 2019. Diversity of carbapenemases in clinical isolates: The emergence of bla VIM-5 in Bangladesh. J Infect Chemother. doi:10.1016/ j.jiac.2019.01.010.

2. Momtaz S, Saha O, Usha MK, Sultana M and Hossain MA. 2018. Occurrence of pathogenic and multidrug resistant Salmonella spp. in poultry slaughter-house in Bangladesh. Biores Comm. 4(2): 506-515.

3. Strobel G and Daisy B. 2003. Bioprospecting for microbial endophytes and their natural products. Microbiol Mol Biol Rev. 67(4): 491-502.

4. Suresh K,Senthilkumar PK and Karthikeyan B. Antimicrobial activity of aegle marmelos against clinical pathogens. J Phytol. 2009.

5. Islam MM. 2019. Varietal advances of jute, kenaf and mesta crops in Bangladesh: A review. Int J Bioorganic Chem. 4(10): 24-41.

6. Ben Yakoub AR, Abdehedi O, Jridi M, Elfalleh W, Nasri M and Ferchichi A. 2018. Flavonoids, phenols, antioxidant, and antimicrobial activities in various extracts from Tossa jute leave (Corchorus olitorus L.). Ind Crops Prod. 118: 206213.

7. Zakaria ZA, Somchit MN, Zaiton H, Mat Jais AM, Sulaiman MR, Farah WO, Nazaratulmawarina R and Fatimah CA. 2006. The in vitro antibacterial activity of Corchorus olitorius extracts. Int J Pharmacol. 2(2): 213-215.
8. Azuma K, Nakayama M, Koshioka M, Ippoushi K, Yamaguchi Y, Kohata K, Yamauchi Y, Ito H and Higashio H. 1999. Phenolic antioxidants from the leaves of Corchorus olitorius L. J Agric Food Chem. 47(10): 3963-3966.

9. Adegoke AA and Adebayo-Tayo BC. 2009. Phytochemical composition and antimicrobial effects of Corchorous olitorius leaf extracts on four bacterial isolates. $J$ Med Plants Res.3(3): 155-159.

10. Dorta E, Lobo MG and Gonzalez M. 2012. Reutilization of mango byproducts: Study of the effect of extraction solvent and temperature on their antioxidant properties. J Food Sci.77(1): C80-88.

11. Oboh G, Raddatz H and Henle T. 2009. Characterization of the antioxidant properties of hydrophilic and lipophilic extracts of Jute (Corchorus olitorius) leaf. Int J Food Sci Nutr. 60(Suppl 2): 124-134.

12. Ohashi K, Watanabe H, Okumura Y, Uji T and Kitagawa I. 1994. Indonesian Medicinal Plants. XII. Four Isomeric Lignan-Glucosides from the Bark of Aegle marmelos (Rutaceae). Chem Pharm Bull. 42(9): 1924-1926.

13. Holder IA and Boyce ST. 1994. Agar well diffusion assay testing of bacterial susceptibility to various antimicrobials in concentrations nontoxic for human cells in culture. Burns.20(5): 426-429.

14. Islam T, Otun Saha SS, Hridoy M, Hasan M, Marzan S and Rahman MM. 2017. Comparison between reduced susceptibility to disinfectants and multidrug resistance among hospital isolates of Pseudomonas aeruginosa and Staphylococcus aureus in Bangladesh. Bagcilar Med Bull. 2(4): 88-97.

15. SPSS I. PASW statistics for windows, version 18.0. Chicago SPSS Inc. 2009.

16. Islam MM. Biochemistry, Medicinal and Food values of Jute (Corchorus capsularis L. and C. olitorius L.) leaf: A review. Int J Enhanc Res Sci Technol Eng. 2(11) 35-44.

17. Al-Snafi AE. 2016. The contents and pharmacological importance of Corchorus capsularis-A review. IOSR J Pharm.6(6): 58-63. 